\title{
Srpska pravoslavna crkva, desekularizacija i demokratija
}

Aвstract: Vukomanović Milan, Srpska pravoslavna crkva, desekularizacija i demokratija (Serbian Orthodox Church, Desecularization and Democracy). "Poznańskie Studia Slawistyczne" 10. Poznań 2016. Publishing House of the Poznań Society for the Advancement of the Arts and Sciences, pp. 269-279. ISSN 2084-3011.

In Serbia, in the aftermath of 5 October 2000, the process of desecularization, including the revitalization of the Serbian Orthodox Church (SOC), overlapped with the democratization of its political institutions, as well as with the political and social pluralism. The desecularization of the Serbian society had already started in the socialist Yugoslavia, but the process itself intensified in the early period of political pluralism and establishment of the democratic political institutions. Is Orthodoxy compatible with democracy, viewed not only as the will of the majority or an election procedure, but also as a political culture of pluralism and rule of law? Is Orthodoxy possible as a "civic" church, in line with the European political tradition of democracy and pluralism? The author contends that the contemporary Orthodoxy, including the SOC, accepts globalization in its technical, technological and economic sense, with a parallel tendency towards cultural fragmentation. Thus one needs a consensus between the SOC, state and society in Serbia concerning the basic values, such as: democracy, civil society, pluralistic discourse, secular tolerance and individual human rights.

KeYwords: Serbian Orthodox Church; desecularization; democracy; religiosity; Church - state relations; Serbia

\section{1.}

U Srbiji se nakon 5. oktobra 2000. godine proces revitalizacije religije poklopio s demokratizacijom njenih političkih institucija i pratećim političkim i društvenim pluralizmom. Desekularizacija srbijanskog društva otpočela je još u socijalističkoj Jugoslaviji, ali se sam taj proces intenzivirao u periodu začetka političkog pluralizma i nastojanja da se ustanove i stabilizuju demokratske političke institucije. U periodu nakon oktobarskih promena 2000. godine najveća religijska organizacija u Srbiji, Srpska 
pravoslavna crkva (SPC), počela je u svojoj matici da stiče i prva iskustva s modernom, mada nestabilnom, demokratijom. Država i većinska crkva su gotovo preko noći zasnovale odnos koji im u prošlosti nije bio poznat. Reč je tu o iskustvu crkve s jednom demokratskom državom. Pre toga SPC je imala posla s autoritarnom državom miloševićevskog tipa, a još ranije s državom u kojoj je vladao jednopartijski sistem, gde su jedna ideologija i partija imale strukturalni monopol nad državom i društvom. Najzad, pre Drugog svetskog rata, u relativnoj harmoniji našle su se monarhija i SPC kao njena državna crkva.

U ovom veku nastupile su, međutim, brojne promene u odnosima države i verskih zajednica u Srbiji. Navedimo samo neke od tih promena: 1) revitalizacija religijskog života: religija više nije samo stvar privatnosti, već ona ima svoje mesto u javnoj sferi; 2) novi zakon o verskim slobodama (2006) izmenio je pravni položaj i status verskih zajednica; 3) obnova verskih institucija i hramova; 4) religije su zadobile svoje mesto u javnim servisima i privatnim medijima, a počele su da emituju i svoje programe na verskim radio i TV stanicama; 5) verske zajednice dobijaju finansijsku pomoć i poreske olakšice od države, a postepeno im se vraća i nacionalizovana imovina; 6) povratak konfesionalne veronauke u javne škole; 7) učešće verskih zajednica u socijalnom radu i filantropiji; 8) nova normativna uloga verskih zajednica, uključujući i njihovu etičku, ali i političkosimboličku funkciju u društvu.

U ovom periodu SPC je sve više počela da pruža novi ideološki okvir za državne institucije kao što su, na primer, vojska ili škola, popunjavajući, na svoju vlastitu inicijativu ali i uz podršku države, ideološki vakuum koji je nastao nakon sloma komunizma. Međutim, njena važnija, socijalna uloga nije tu još uvek sasvim jasna. Puno prostora koji zakonski pripada verskim zajednicama (filantropija, zadužbinarstvo, humanitarni i socijalni rad i sl.) ostaje neiskorišćeno, dok se, s druge strane, lako vrši politizacija ili politička instrumentalizacija crkve koju ne vrše samo konzervativni političari, već i njeni vlastiti arhijereji i sveštenici.

Još ozbiljniji problem predstavlja nedostatak pravog kontakta SPC s društvom u Srbiji, i to s građanskim društvom, autonomnim individuama koje imaju svoja prava, zasebne interese i raznolike identitete kreirane životom u savremenom pluralnom svetu. Zanimljivo je da je SPC ostvarila zavidan odnos sa srbijanskom državom, ali da, nažalost, još uvek nema 
pravi kontakt s (civilnim) društvom, kakav je, na primer, imala Rimokatolička crkva u Poljskoj još pre svrgavanja komunizma. Predstavnici SPC, doduše, redovno spominju narod, ali to je gotovo metafizička kategorija, jedan neizdiferencirani kolektiv, poput antičkog hora. S jedne strane, tu je reč o izvesnom nesnalaženju crkve u novim uslovima. S druge strane, vidljiva je i određena politička teologija i ideologija SPC, koja je dugo bila u drugom planu, samim tim što je crkva u vreme socijalizma bila slabo prisutna u javnosti.

Istorijski gledano, SPC, kao i većina drugih pomesnih pravoslavnih crkava, razvijala se u političkim kontekstima koji su bili bitno nedemokratski (srednji vek, Vizantija, osmanska osvajanja i dr.). Kao posledica toga, javile su se preterana hijerarhijska kontrola i dominacija, pasivnost sveštenika i indiferentnost laika. Ono što je sada tu novo - i što je crkva imala prilike da iskusi jedino u dijaspori, $\mathrm{u}$ demokratskim državama u kojima su njene eparhije još ranije bile prisutne - jeste čitav niz otvorenih pitanja i problema koji se tiču toga šta je demokratija, modernost, nacionalna kultura, pluralizam, civilno društvo, kao i šta sve podrazumevaju odnosi između verskih zajednica i države u tim novim uslovima. Na primer, koji društveni problemi spadaju u domen crkvene nadležnosti i njenih ustavnih okvira i ograničenja? Koliko su verske zajednice u stanju da se bave tim problemima i kakav kapacitet one imaju za njihovo eventualno rešavanje? Koliko su odgovori crkve relevantni i aktuelni kada je reč o savremenim političkim i društvenim pitanjima? Ukoliko je, recimo, pridruživanje Evropskoj uniji (EU) cilj većine građana Srbije i njihovih političkih predstavnika, promovisanje antievropskog diskursa od strane SPC stavlja njene vernike, kao građane te države, u izvestan procep. Prema istraživanju o odnosu građana Srbije prema evropskim integracijama iz 2010. godine (Religioznost građana 2011), uključivanje Srbije u EU najviše podržavaju upravo tradicionalni vernici (89\%), dok je podrška među ambivalentnim ispitanicima 67\%, a među ateistima 60\% (Radisavljević-Ćiparizović 2011). Čak i ako se ovi postoci čine previsokim za 2010. godinu, možemo li ipak reći, s obzirom na čestu kritiku EU iz redova crkvene hijerarhije, da je tu religijska zajednica u koliziji s religijskom institucijom, njenim evroskepticizmom? Da li se tu zapravo institucija, crkvena hijerarhija, odupire evropskim integracijama, dok zajednica (tradicionalnih) vernika nije sklona da prihvati takav stav crkvenih autoriteta? 
Kakva je, potom, crkvena vizija savremenog društva? Kakav je njen odnos s civilnim društvom: da li verske zajednice sebe doživljavaju kao deo civilnog društva ili ne? U vreme socijalizma država je, politički i ideološki gledano, prilično jednostrano određivala prirodu svog odnosa s verskim zajednicama. U postsocijalističkom periodu je došlo do značajnog proširenja religijskih prava i sloboda crkava i verskih zajednica, ali to je odmah nametnulo i pitanje njihove povećane odgovornosti u mnogim oblastima. Moglo bi se onda reći da je i u Srbiji u 21. veku došlo do šireg političkog, društvenog i kulturnog preispitivanja uloge religije i crkve, dok su tradicionalne verske zajednice (ponajviše SPC) u svojoj „odbrani kulture” počele učestvovati u preoblikovanju klasičnog modernizacijskog koncepta, njegovog uvijanja u lokalno, nacionalno, partikularno kulturno ruho.

Postsocijalistička društva u Evropi su se, u periodu svoje društvene transformacije, prilično nedvosmisleno opredelila za desekularizacijski model koji favorizuje klasične, crkvene vidove religioznosti. Za razliku od Zapadne Evrope, gde tradicionalne, istorijske crkve nisu više u mogućnosti da kao institucije ,disciplinuju” veliki deo stanovništva (Davie 2007: 96), one u Centralnoj i Istočnoj Evropi velikim delom učestvuju u obnavljanju tradicionalnih kulturnih modela i obrazaca. Istorijske crkve (institucije) u Zapadnoj Evropi imaju, na primer, sve manje uticaja na samo stanovništvo, odnosno religijske zajednice. Pa ipak, religija je tu i dalje vrlo živa u svojim neinstitucionalnim oblicima (New Age, novi religijski pokreti, individualna religioznost i sl.), kao i među netradicionalnim zajednicama imigranata, koji svoj identitet bitno konstruišu upućivanjem na odgovarajući religijski diskurs ili praksu poreklom iz matične domovine. U Centralnoj i Istočnoj Evropi su, s druge strane, u usponu tradicionalne religije, i tu, bar na prvi pogled, nema veće diskrepancije između religijskih institucija i samih zajednica, osim u slučajevima manjih raskola koji povremeno uzdrmaju neke pravoslavne crkve.

Prema popisu stanovništva sprovedenom 2011. godine, u Republici Srbiji (bez Kosova) živelo je 7.186 .862 stanovnika. Preko 94\% njih izjasnilo se da pripada nekoj od sledećih veroispovesti: 84,6\% (6.079.396) 
pravoslavnoj; 5\% (356.957) rimokatoličkoj; 1\% (71.284) protestantskoj; $3,1 \%$ (222.828) islamskoj. Broj Jevreja (578) i pripadnika istočnjačkih religija (1.237) daleko je manji od 1\%. Ateista (80.053) i agnostika (4010) ukupno ima svega $1,17 \%$. Pored toga, čak 220.735 stanovnika se uopšte nije konfesionalno deklarisalo (Popis stanovništva 2013: 14, 47).

Sociolozi religije odavno upozoravaju na to da konfesionalna samoidentifikacija nije, ipak, isto što i intrinsična, aktualna (prava, stvarna) religioznost. Većina istraživača koja se bavila tim pitanjima slaže se da je u Srbiji od 90-ih godina prošlog veka ustanovljen stabilan trend u pogledu religijskih promena. Broj ateista je izrazito opao, a u svakodnevni život je vraćena verska praksa. Uočene su i promene u profilu tipičnog vernika. Dok su rezultati ranijih ispitivanja ukazivali na nešto veći postotak religioznosti kod žena, kao i građana iznad 60 godina starosti, poljoprivrednika, radnika, domaćica, manje obrazovanih građana, danas tipični vernik može biti iz seoske, ali i gradske sredine, starija ili mlađa osoba, neobrazovano ili obrazovano lice. Istraživanja s kraja 90 -ih i početka novog milenijuma pokazala su, uz izvesna odstupanja, da se tek oko četvrtine građana Srbije može smatrati religioznim ili uverenim vernicima, s preko $30 \%$ konformističkih vernika, oko $30 \%$ agnostika i oko $15 \%$ nereligioznih građana (Radisavljević-Ćiparizović 2002, 2006: 67).

Novija ispitivanja su, isto tako, pokazala da kod punoletnog stanovništva Srbije religioznost raste, ali da nju većina građana vezuje za pripadnost naciji ili tradiciji, a ne za verovanje u Boga. U svesti vernika temeljne postavke pravoslavnog učenja prilično su nejasne, a postoji i znatan broj onih koji nisu sigurni u svoju religioznost. To, uostalom, potvrđuje i popis iz 2011. godine, prema kome se skoro četvrt miliona stanovnika nije uopšte konfesionalno deklarisalo. Believing without belonging (verovanje bez pripadanja) kovanica je koju koristi sociološkinja religije Grejs Dejvi (Davie 2005: 68) da bi objasnila necrkveni karakter religioznosti u Zapadnoj Evropi i povećanu individualizaciju religijskog života. U slučaju Srbije bismo, zbog značaja koji konfesionalna pripadnost ima za kolektivni identitet, pre možda mogli govoriti o pripadanju bez (dubljeg) verovanja, naročito kada se podaci o konfesionalnoj pripadnosti uporede s istraživanjima stvarne, intrinsične religioznosti na osnovu većeg broja složenijih indikatora.

U istraživanju iz 1999. godine (Radisavljević-Ćiparizović 2006) religijska samoidentifikacija u Srbiji kretala se od 60\% religioznih građana, 
preko $21 \%$ neopredeljenih, do $19 \%$ nereligioznih. Kada se ti rezultati uporede $\mathrm{s}$ istraživanjem iz 2010. godine, broj religioznih se povećao na $78 \%$, broj neopredeljenih je pao na 4\%, dok je nereligioznih ukupno $14 \%$ (Radisavljević-Ćiparizović 2011: 28). Precizniji podaci o konfesionalnoj samoidentifikaciji iz 2010. godine pokazuju, međutim, da je tzv. tradicionalnih vernika bilo $39,1 \%$, a uverenih vernika (koji prihvataju sva učenja vere) $27,8 \%$, sa još $16,4 \%$ onih koji ne prihvataju sva načela svoje vere. Neopredeljenih, ravnodušnih, nereligioznih i ateista ima ukupno 16,6\%. Kada je pak reč o aktualnoj religioznosti, ,,crkveno religioznih”, prema istraživanju iz 2010. godine ima svega 10\% (Radisavljević-Ćiparizović 2011: 30).

Prema Svetskom istraživanju vrednosti (WVS 2001) i Evropskom istraživanju vrednosti (EVS 2008) koje je sprovedeno i u Srbiji, broj konfesionalno (samo)identifikovanih pravoslavnih vernika prevazilazi samodeklarisanu religioznost ispitanika, što znači da konfesionalnost u percepciji ispitanika nije nužno povezana s ličnom religioznošću (Blagojević 2010: 140). U Srbiji je konfesionalna samoidentifikacija redovno masovnija pojava od religijske samoidentifikacije, naročito kod pravoslavnog stanovništva. To uostalom potvrđuju i istraživanja iz 2010. godine (Blagojević 2012: 46). Redovnost ispunjavanja verskih dužnosti sa stanovišta institucionalizovane religije se podrazumeva, ali je stvarna verska aktivnost nedovoljno izražena. To se odnosi i na prihvatanje postavki „dogmatskog jezgra hrišćanstva" (Blagojević 2012: 49). Srbija se, najzad, prema stepenu posećenosti hramovima (7\%) nalazi na samom dnu liste evropskih zemalja, iza Poljske, Slovačke, Italije, Belgije, Austrije, Velike Britanije, Hrvatske, Francuske, Rumunije, Češke, Bugarske, ali ispred Rusije (cf. Church attendance).

Globalna studija Gallup International s kraja 2011. godine (Petrović 2012: 9) ${ }^{1}$ pokazuje, navodno, da su građani Srbije ,izuzetno religiozni” $\mathrm{u}$ poređenju s građanima iz drugih evropskih zemalja. Ispred njih su, po indeksu religioznosti, samo stanovnici Makedonije, Rumunije, Moldavije i Poljske. Čak 77\% građana Srbije sebe smatra religioznima ukoliko im se postavi pitanje: „Bez obzira na to da li odlazite na mesta bogosluženja ili ne, da li biste za sebe rekli da ste religiozna, nereligiozna osoba ili ubeđeni

${ }^{1}$ Ovde je reč o globalnom ispitivanju za Gallup International Religiosity and Atheism Index iz novembra i decembra 2011. godine sa 52.000 ispitanika iz 57 zemalja sveta. 
ateista?". Ovakvo pitanje ima malo smisla kada je reč o religioznosti i nije nikakav pouzdan indikator. Navedeno pitanje zapravo implicira da ispitanici iz Galupovog istraživanja ne moraju: 1) pripadati nekoj religijskoj zajednici ili instituciji; 2) obavljati bogosluženje, religijsku praksu; 3) koristiti religijski govor u svakodnevnom životu. U slučaju Srbije - s obzirom na visok postotak konfesionalne samoidentifikacije koji se redovno ispoljava na popisima stanovništva, u javnomnjenjskim, ali i specijalizovanim sociološkim ispitivanjima religioznosti - moglo bi se pretpostaviti da ispitanici iz navedenog istraživanja sebe, ipak, u izvesnom smislu smatraju pripadnicima neke religijske zajednice (npr. pravoslavnim ili katoličkim hrišćanima, muslimanima itd.), bez obzira na njihovu stvarnu, intrinsičnu religioznost. Sasvim je sigurno, međutim, da bi odgovor na pitanje ,koliko religija ima uticaja na vaš svakodnevni život", tu povlačilo puno niži postotak religioznosti.

\section{3.}

Da li je pravoslavlje kompatibilno s demokratijom, shvaćenom ne samo kao volja većine ili izborna procedura, nego i kao politička kultura pluralizma i vladavina prava? Da li je moguće nekakvo „civilno” pravoslavlje koje bi više bilo u skladu s evropskom demokratijom i pluralizmom? Takva civilna religija bi bila kompatibilna s demokratijom, ali jedan dogmatski esencijalizam, koji odbacuje mogućnost kulturne promene, svakako ne bi. Na primer, ideja o Božjem suverenitetu („Carstvo nebesko”), jedna politička teologija, postavila bi se tu naspram političke filozofije Zapada, prosvetiteljskog koncepta Velikog odvajanja formulisanog još u doba Tomasa Hobsa (Vukomanović 2008: 43). Najveći protivnik takve političke teologije, u očima mnogih pravoslavnih teologa, jesu zapravo sekularne vrednosti Zapada. Stavovi vodećih srpskih teologa Nikolaja Velimirovića i Justina Popovića prema sekularnom i „dehristijanizovanom” Zapadu i Evropi dobro su poznati i često citirani i u radovima savremenih pravoslavnih bogoslova. Čak i umereniji episkopi su još uvek skloni vrlo kritičkoj recepciji zapadnih vrednosti.

Reklo bi se da savremeno pravoslavlje, bar u balkanskom kontekstu, prihvata globalizaciju u tehničkom, tehnološkom, pa i ekonomskom 
smislu, ali istovremeno teži ka kulturnoj fragmentaciji, jer kultura je kao sistem značenja i simboličkih relacija - uvek specifična, unikatna, lokalna (Tibi 2008: 19). U tom smislu, globalizacija u nezapadnim društvima ne mora nužno podrazumevati prihvatanje zapadnih kulturnih vrednosti i normi. Jer one danas podrazumevaju i sekularne vrednosti civilnog društva koje nije hrišćansko (pravoslavno, katoličko), ali ni islamsko, jevrejsko, već internacionalno. Tu se postavljaju zahtevi za ljudskim pravima koja bi mogla biti utemeljena na zajedničkim sekularnim vrednostima i demokratskoj političkoj kulturi. Zbog toga je potreban i konsenzus između pravoslavlja i sekularne političke filozofije oko temeljnih vrednosti kao što su: demokratija, civilno društvo, pluralistički diskurs, sekularna tolerancija $\mathrm{i}$ individualna ljudska prava. Kulturni diverzitet je dragocen, ali on ima jasne granice kada dođe u suprotnost s navedenim vrednostima. I multikulturalizam koji deluje $\mathrm{u}$ ime kulturnog diverziteta treba da respektuje ljudska prava, on ne može da bude doktrina prema kojoj je u ime kulture sve dozvoljeno. Da li bi, možda, koncept civilnog pravoslavlja (za razliku od političkog pravoslavlja kao jedne vrste političke teologije) imao temelja u samoj toj tradiciji? Sekularni racionalizam, svakako, nije stran pravoslavlju, naročito u zapadnim eparhijama pravoslavne crkve, a možda još više tokom perioda socijalizma u Centralnoj i Istočnoj Evropi.

Religija danas stupa u različite, vrlo složene interakcije s ideološkim, političkim, kulturnim i ekonomskim sistemima. Ona je, štaviše, sastavni deo globalizacijskih procesa. S druge strane, ona još uvek - posredstvom svojih institucija, njihove interpretativne strategije - pruža sigurno utočište za „odbranu kulture”, nacionalnog, lokalnog, partikularnog. Tu je reč, u stvari, o zaštiti religijskog interpretativnog nasleđa koje pre svega afirmiše versku instituciju (npr. SPC kao ,vekovnog čuvara srpske kulture, tradicije, ćiriličnog pisma" itd.). Kulturni identitet nije, međutim, dovoljan preduslov za politički identitet (Majer 2009: 51).

U Srbiji je danas i među mlađim generacijama vaspitavanim u duhu pravoslavlja vidljiv izvestan otklon prema pluralističkom modelu društva koji je, zapravo, tekovina prosvećenosti, kao i opredeljivanje za jedan monistički, arhajski, zavetni obrazac nacije i države ${ }^{2}$. Oživljavanje, na po-

${ }^{2} \mathrm{O}$ tome možda najbolje svedoči dokument poznat kao Predlog Načertanija nacionalnog programa Omladine srpske za 21. vek (Vukomanović 2008: 125-126). Slično je intoniran 
četku 21. veka, monističkog zavetnog obrasca i principa sabornosti (kao svojevrsnih postsocijalističkih hibrida) ima za rezultat kritiku srpskih prosvetitelja poput Dositeja, ili pluralistički i evropski orijentisanih „novih ideologa”, „novodobaca”, nezavisnih intelektualaca i aktivista u nevladinim organizacijama (Vukomanović 2008: 128; 2011: 165). Nasuprot takvom konceptu, neki visoki predstavnici SPC smatraju da se treba vratiti starom modelu sabornosti (Vukomanović 2011: 165).

U svetu koji karakteriše velika dislociranost, izmeštanje etničkih, religijskih i, uopšte, kulturnih manjina religijske institucije su moćni čuvari grupnih, kolektivnih identiteta. To važi i za društva u procesu transformacije, kao što je društvo u Srbiji. Na izazove modernizacije i sekularizacije religijske i crkvene institucije danas neretko odgovaraju religizacijom modernosti. A etnifikacija i religizacija politike uvek su izazov za individualna, ljudska prava. Kultura moderne počiva, međutim, na Velikom odvajanju vere i razuma, pri čemu je oblast razuma i znanja prepuštena individualnom tumačenju. Ta kultura se, prema rečima nemačkog politikologa Tomasa Majera, ,principijelno razlikuje od tradicionalne zapadne [ali i pravoslavne - M.V.] kulture u Evropi po svojim osnovnim stavovima, po metafizici, socijalnoj ontologiji, principima društvenog legitimiteta i po političkim vrednostima i institucijama" (Majer 2009: 61). Utoliko je moderna Evropa mogla da nastane ,tek kada je u svemu što se ticalo političkog uređenja zajednice sasvim revolucionarno odbacila hrišćansko poimanje društvenih odnosa" (Majer 2009: 65).

Za procenu društvenog i političkog uticaja religije nije presudno to da li ona u svom kulturnom miljeu ima veći ili manji značaj, nego na kom nivou se ona javlja i na koji način učestvuje u tom miljeu. Tomas Majer (2009: 72) tako razlikuje bar tri nivoa njenog delovanja: 1) pripisivanje metafizičkog smisla i očekivanja spasenja (ways of believing); 2) individualno i kolektivno vođenje kroz život: praksa, običaji, etika življenja, rituali, estetika i dr. (ways of life); 3) osnovne društvene i političke vrednosti za suživot sa drugima (ways of living together). U tom trećem slučaju je reč

i proglas Prvog sabora pravoslavno-nacionalne omladine srpske na Beogradskom univerzitetu od 6.12.2001. godine pod nazivom Zavetne dveri - Pozicija nacionalne omladine (Vukomanović 2008: 127-128). 
o osnovnim vrednostima za zajednički život različitih ljudi u istom društvu $\mathrm{i}$ istoj političkoj zajednici.

Prvi Majerov nivo označili bismo ovde kao nivo religijskog (teološkog) diskursa, drugi kao nivo prakse i ethosa, a treći kao nivo učešća zajednice vernika i religijske institucije u javnoj sferi, uključujući tu i pokušaj njihovog uticaja na praktične politike. U kontekstu Srbije, političko pravoslavlje, na primer, odbacuje sekularne vrednosti i demokratsku političku kulturu i utoliko je ono, u osnovi, antievropsko, što se sasvim jasno vidi iz govora paraklerikalnih organizacija, crkvene hijerarhije, pa čak i iz saopštenja nekih političkih partija (Vukomanović 2011). Napred smo, uostalom, već ukazali, na osnovu novijeg empirijskog istraživanja (2010), da česta kritika EU iz redova crkvene hijerarhije pokazuje da je zajednica pravoslavnih vernika u Srbiji u nekoj vrsti kolizije s religijskom institucijom (SPC) i njenim evroskepticizmom. Crkvena hijerarhija se, naime, odupire evropskim integracijama i, u krajnjoj liniji, evropskoj moderni, dok zajednica (tradicionalnih) vernika nije sklona da prihvati takav stav svojih crkvenih autoriteta.

Funkcija demokratije u pravnoj državi jeste da se obezbedi onaj minimum na poslednjem, trećem nivou, na osnovu koga će na prva dva nivoa biti omogućen, i na duži rok zagarantovan, maksimum razlika (Majer 2009: 74). Osnova pravne države i demokratije se pak narušava kada većinska (,primarna”) kultura na esencijalistički način ugrožava prava drugih na sopstveni identitet (Majer 2009: 75). Sasvim bih se složio s Majerom u njegovoj tezi da za demokratiju u pravnoj državi nije potreban konsenzus na prvoj i drugoj spomenutoj ravni, ,već je samo bitno da [prve dve ravni M.V.] budu principijelno usklađene s trećom ravni, a ona će opet sopstveni legitimitet dovesti u pitanje ako izađe iz svojih okvira" (Majer 2009: 75).

Konsenzus oko političkih vrednosti ne znači nužno i gubitak kulturnog identiteta, kompromitovanje kulturnih vrednosti i posebnosti. Tu onda i pravoslavlje može naći svoje mesto u okviru pluralnog koncepta modernosti. Na Zapadu je danas prisutno mnoštvo različitih kulturnih identiteta i taj diverzitet se prihvata kao stanje stvari. Ujedno postoji i potreba da se postigne konsenzus oko političkog identiteta političkih zajednica, država. Naglasak je tu, pre svega, na konsenzusu oko demokratske političke kulture. Ona treba da bude dovoljno inkluzivna za kulturni i religijski diverzitet, ali da se pritom kolektivna kulturna prava ne 
postavljaju iznad demokratije, vladavine prava, odnosno ljudskih prava građana u sekularnoj državi.

\section{Literatura}

Blagojević M., 2010, Vezanost za pravoslavlje u ogledalu statistike: sociološko merenje crkvenosti, „Teme” br. 1, str. 131-154.

Blagojević M., 2012, Religijsko-konfesionalna identifikacija i vera u Boga građana Srbije, ,Filozofija i društvo” vol. 23, br. 1, str. 40-52.

Church attendance, <http://www.nationmaster.com/country/yi-serbia-and montenegro>, 10.11.2014.

Davie G., 2005, Europe: The Exception that Proves the Rule?, u: The Desecularization of the World: Resurgent Religion and World Politics, ur. P. Berger, Grand Rapids, str. $65-83$.

Davie G., 2007, The Sociology of Religion, London.

EVS - European Values Study, Serbia, 2008, <http://www.europeanvaluesstudy.eu>, 5.12.2013.

Majer T., 2009, Identitet Evrope, Beograd.

Petrović M., 2012, Građani Srbije peti u Evropi po religioznosti, „Blic” 29.7.2012, str. 9.

Popis stanovništva, domaćinstava i stanova 2011. u Republici Srbiji: Stanovništvo: Veroispovest, maternji jezik i nacionalna pripadnost. Podaci po opštinama i gradovima, 2013, Beograd.

Radisavljević-Ćiparizović D., 2002, Religija i svakodnevni život: vezanost ljudi za religiju i crkvu u Srbiji krajem devedesetih, u: Srbija krajem milenijuma, ur. S. Bolčić, A. Milić, Beograd, str. 215-248.

Radisavljević-Ćiparizović D., 2006, Religioznost i tradicija, Beograd.

Radisavljević-Ćiparizović D., 2011, Religioznost građana Srbije i njihov odnos prema EU-sociološki ugao, u: Religioznost građana Srbije i njihov odnos prema procesu evropskih integracija, Beograd.

Religioznost građana Srbije i njihov odnos prema procesu evropskih integracija, 2011, Beograd.

Tibi B., 2008, Political Islam, World Politics and Europe, London.

Vukomanović M., 2008, Homo viator: religija i novo doba, Beograd.

Vukomanović M., 2011, Serbian Orthodox Church Between Traditionalism and Fundamentalism, u: Fundamentalism in the Modern World, vol. 1, ur. U. Mårtensson et al., London, str. 148-170.

WVS - World Values Survey, 2001, <www.worldvaluessurvey.org> Online Data Analysis, $<$ http://www.wvsevsdb.com/wvs/WVSAnalizeQuestion.jsp>, 10.12.2013. 